\title{
Meeting the Crisis in Health Manpower
}

\author{
GEORGE JAMES, M.D., M.P.H.
}

W E ARE DEALING here with the future. Even if all we now recommend is accepted, it will take time for it to become law and additional time to become action. It will take time for persons to be trained under the programs we recommend and more time before the results of that training are applied in the field. The period of service of these programs will extend many years from now, carrying our concepts into a new world.

The health situation then will be different from that of today. The professions dealing with it will also be different. No doubt we shall still have physicians and nurses, but what they and the holders of other titles actually do will change a great deal. The amount of variation in the roles of medical workers in the last few decades is an indication of what may lie ahead.

Our government has recently brought about tremendous changes in the demand for, and the character of, medical care without effecting any drastic improvements to meet the new and varied needs for more medical administrators, more planners, more nursing care administrators, more health economists, and more persons skilled in health services research.

\section{Delineating Our Future Health Problems}

What we need to know is not what manpower shortages exist, how many medical schools there are, or what duties of the professional nurse might be taken over by some subprofessional. The most important question is what the health picture will be in the next two decades, and what will be the difficulties which we must be prepared to meet.

The next most important question is what will we be willing to do about it? The latter question goes to the basis of policy and of public value systems and priorities. We have made a modest start toward implementation of the concept that all our people are entitled to the health services they need when they need them. The alternate is that the privilege of health is only for the few. To accept privilege as a basis for the quality or quantity of health care means the acceptance of two medical systems-one for the privileged and a second, less effective system for people certified as not privileged. This concept, under which we have long been operating, has been rejected philosophically by a majority of our people and rejected in practice by our Federal and State governments.

But at the present stage of development of these governmental programs we are emphasizing the quantitative element in medical care. Our vast Federal programs are increasing the demand for the varieties of care now offered without as yet fully accepting the responsibility for improving the quality of care. It is obvious that the next 5 years will bring dramatic shifts in this emphasis. Legislation currently under consideration by Congress already points in this direction. Improvement in the quality of our health manpower is one major way we can improve the quality of medical care. This assertion is the only answer to the all too valid excuse that high-quality care cannot now be mandated

Dr. James, dean of the Mount Sinai School of Medicine, New York, N.Y., presented the speech on which this paper is based at the Third National Conference on Public Health Training held in Washington, D.C., August 17, 1967. 
because it does not yet exist in sufficient supply to meet the demand.

The persons who train under the programs we are considering at this conference will work in a period in which high-quality care for all will be the practical aim. We ought, therefore, to train our people for that kind of future situation and not for a perpetuation of what is wrong in our present medicine.

The future will bring many questions about the value systems of the public and the priorities of specific health problems. Sir Geoffrey Vickers (1), in a now familiar comment, said that public health moves forward by successive redefinings of the unacceptable. Within most of our lifetimes, for example, we have made it unacceptable for people to have smallpox or diphtheria.

We have not made it unacceptable, however, for a person to follow a diet that increases his chances of coronary thrombosis; nor have we made it unacceptable for people to smoke the cigarettes that may push them to lung cancer.

Where will our unacceptability threshold lie in the next decades? Will we make it unacceptable for the Negro baby in Harlem to have four times the risk of the average white baby of dying before 1 year of age? Can we finally make it unacceptable for syphilis and gonorrhea to flourish in a nation that knows perfectly well how to cure but not how to prevent these diseases?

Death and disability rates do not adequately describe health problems. There are questions of relative pain and discomfort and of the duration of a disease. Individual responses to disease processes vary widely. A certain amount of arthritis may all but destroy the productive life of a baseball player. The same amount, however, might scarcely cause a ripple in the life of a desk executive. The social setting, rather than the extent of the disease process, often determines the disability of the patient-or, to be more accurate - a combination of the two factors.

We use the past and the present to predict the future. If we study the present situation in relation to the past, we can already discern the broad outlines of the future we are preparing for and can see how different it will be. Some examples of these differences follow.

The medicine of yesterday was designed for acute illness, mostly infectious. The medicine of the future will be designed for much chronic illness and for filling the needs for health maintenance.

In the medicine of yesterday, illness was generally due to natural hazards. In the medicine of the future, illness will be increasingly promoted by manmade hazards.

There were few Federal programs in the medicine of yesterday. The medicine of the future will be characterized by extensive Federal programs.

In the medicine of yesterday, solo practice was supreme. The physician worked alone or with a nurse. In the medicine of the future, there will be a decline in solo practice. Both the physician and nurse will have more helpers. The tendency will be toward team practice.

In the medicine of yesterday, sanitation was a simple problem of pure food and water. The medicine of the future will face the complicated problems of man's progressively increasing pollution of his environment and of dealing with the complex environmental hazards of urban living.

In the medicine of yesterday, one waited for symptoms. In the medicine of the future, rising attention will be paid to the presymptom period.

In the medicine of yesterday, there was relatively simple instrumentation. The medicine of the future will probably use complicated instrumentation, computers, cardiac pacemakers, and the like.

The medicine of yesterday served a large rural population. The medicine of the future will largely serve people living in urban areas.

In the medicine of yesterday, public health was considered to be separate from private practice and remote from patient care. In the medicine of the future, public health will be involved in patient care, and private practitioners will participate in public health.

The medicine of yesterday emphasized illness rather than the social situation. In the medicine of the future, the social situation will be seen as intimately related to health levels.

All of these changes are known. All of them should affect the present and future training of health personnel. All suggest kinds of activity for which today's health personnel are in general not being adequately trained. All sug- 
gest that our health personnel requires extensive retraining to be fully effective in meeting today's health problems.

\section{Defining Public Health Training}

This conference has been given two proposed definitions, one for public health and one for public health training. Public health is defined as "Those services whose provision requires community action" and public health training as "specialized training required by professional personnel employed in the provision of public health services within the community to assure both competent and effective delivery of those services."

But is public health something essentially restricted to an organization or group of organizations? Or is it rather community medicine, whoever is involved? If public health is only what is performed by health departments plus certain health agencies, then wo separate it from a good deal of medicine and especially from the practicing physician.

All medical resources are, or ought to be, brought to bear on public health in one way or another. When we say that public health training is "specialized training required by professional personnel employed in the provision of public health services within the community," we must be sure not to imply that we are giving up the education of people about public health simply because they do not work for a public health organization. Some of those who do not work for a public health organization are definitely a part of our organized community effort-and are becoming more so; these people, too, require extensive public health training.

In fact, it is often more important to inject public health information into the minds of those outside the field than those within it. The physician who refuses to report his syphilis cases to his local health department is typical of our failure in this area.

The designers of the buildings and housing developments where older people will live need exposure to public health. Executives of highway departments who cling to the idea that excessive speed is the only significant factor in automobile accidents need training in public health. Social workers certainly need it. Law enforcement authorities who deal with the problem of narcotic addiction need some background in public health. Welfare workers make contact with public health every day and certainly see the problems. Since, however, they often must help patients thread their way through the medical care jungle, they, too, would probably benefit from more knowledge of public health and, particularly, of the nature and extent of community health resources.

\section{Personnel for Tomorrow's Health Care}

So far as disease control is concerned, the American health establishment is marking time. Its rapid earlier advance in saving lives has stopped. Life expectancy has been practically constant for a couple of decades, and so has the death rate. Hidden behind this plateau is at least one ominous fact-the spread between the level of health of white and nonwhite infants is widening (2).

We perform miracles with individual patients, but we are not significantly changing the trend of most of our 20 leading causes of death. We face problems arising from multiple causes, many if not most of which are fostered and made worse by human behavior as manifested in eating, exercise, and smoking, as well as in that difficult-to-measure factor called tension, and in many other aspects of human behavior. We must somehow manipulate these factors if we are to progress substantially in the foreseeable future against the disease conditions they promote. Making large numbers of people behave is admittedly difficult. It is, however, potentially more effective in the control of health problems than surgery, vaccination, or water purification.

Many of the most significant factors affecting health are two-sided. 'The electric generating station may spew particulate matter into people's lungs, but it also lights the operating room and the physician's office. A drug that saves lives may at the same time promote new and more virulent microbes. Similarly, corrective measures cannot be confined to the simple pursuit of single goals. The training of the modern health worker must provide him with skills in all of the elements required for effective solution of a problem.

If we are asked who will deal with tomorrow's 
health problems, we think of the physician. For years he himself gave whatever medical care there was. And even today, although some health care is parceled out by welfare departments as though it were a relatively standard commodity like birdseed, the physician should be the leader in health programs-if we are ever to be successful in improving the quality of care. Only when the product finally becomes admittedly excellent and capable of rigid standardization, can we allow a person untrained in medical science to assume control. In health, when so many new research findings must constantly be plowed into service programs, there is no effective substitute to ultimate administration by those trained in biomedical science.

A propensity for dissatisfaction with current medical knowledge and with current methods of medical care should be built into the health training programs of the future. Rather than supplant what is dogmatism in today's medicine with a new orthodoxy, we must teach flexibility of approach, a sensitivity to new knowledge, and a restlessness which demands evaluation of the true usefulness of current health programs. This pressure for improvement is what has made our country great, not any blind adherence to, or apologies for, our current practices.

Despite the need for the physician's leadership, he has tended to retreat from the twentieth century. In this connection I can do no better than to quote the following from the sixth annual Bronfman lecture by Dr. Eveline Burns (3) :

There are three groups within the health services whose decisions will be of crucial importance. The first is the medical profession itself, whose members do indeed have it within their power to withhold from the nation the expert guidance and professional help they could give by constructive participation at every stage in the planning and development of health policies and programs. The events of 1965 have already shown the unfortunate consequences of the withdrawn, narrow professional attitude. Medical men know what makes for good medical care añd high-quality, appropriate health services. In view of the importance attached in leading medical circles to the concept of "comprehensive care," I cannot believe that if the medical profession had been sharing constructively in the planning of both parts of title 18, we would have adopted a system that treats health care as a commodity to be bought in a supermarket, item by item, with a built-in encouragement to the consumer to buy mainly those services for which the cost will be reimbursed. With all the lip service that is given to the primacy of prevention, had the medical profession been active at the planning stage, the act would surely not have excluded periodic health examinations, screenings, immunizations, and eye examinations from the list of reimbursable items.

The alienation of the physician from the main flow of American medical thought must be reversed. If not, he runs the serious risk of being displaced.

However we divide the work that must be done in health, whether in public health, private health, or any other branch of the field, leadership must come from the professional having the most profound knowledge of medicineone who is always willing to consider a change in the program to adjust it to the newest biomedical science. For the foreseeable future, it seems to me that this professional must be the physician-but, of course, the "enlightened" physician.

If the physician is to retain first place in medicine, however, he will have to be effective in the kind of medicine that will be practiced in the future. That medicine will be a very different kind from that practiced today. Its basic differences will not be in methods of payment for care. The difference will be in a reorganization designed to bring people the health care they need and to increase the sophistication of our citizens, of our organizational patterns, and our gadgetry so that people will be able to obtain this care when they need it.

Besides the physician, there are dentists, nurses, physical therapists, X-ray technicians, public health nurses, psychiatric social workers, sanitarians, and many more workers in the health field. In 1900, there were 60 other health personnel for every 100 physicians. By the 1960 census, there were 371. In 1965, Coggeshall (4) estimated that the ratio was 400 other health workers for every 100 physicians.

Some authorities place the ratio even higher. Darley and Somers (5), drawing on the Department of Health, Education, and Welfare "Health Manpower Source Book, Manpower in the 1960's," say that only one health worker in 11 is a physician "if one measures against total employment in the industry." A figure of one in 12 , however, is frequently used $(6)$.

The number of persons assisting the physician in one way or another has obviously gone 
up sharply. If one takes all health workers, including physicians, and measures the growth of this group, one finds that, as Darley and Somers (4) observe, "In the Census Bureau categories, health services ranked as the third largest industry in the nation in 1960, exceeded only by agriculture and construction. Its amazing growth between 1950 and 1960 was 54 percent ... the rate of increase was twice that of population growth. Projections indicate that either health services or education will be the nation's largest consumer of manpower by 1970."

In general, the greatest need is for personnel that it takes the longest to train, for example, physicians, chemists, nurses, and sanitary engineers. Still, we are entitled to wonder if making more efficient and effective use of the enormous total number of health workers-usually estimated at between 3 and 4 million-might not accomplish as much in the foreseeable future as frenetic attempts at recruitment.

If you were handed this huge group, ranging from biochemist to practical nurse, from practicing physician to physician doing personal promotion for a drug house, from physical therapist to hospital design specialist, from electronic equipment expert in the operating room to medical school dean, from pharmacist to sanitary engineer, from psychiatric social worker to prison nurse-if you were handed this extraordinary group and given absolute authority to use it any way you wanted to meet the health problems of the nation, it would be interesting to see what you would do. I cannot help thinking that if you started with this massive human resource and could apply it with open mind to our actual problems, the way you would choose to use these people would be very different from the way they are used at present.

This thought has the unreality of a chess problem, of course, since the human beings who constitute our resource of personnel have no intention of allowing themselves to be moved at will. Nevertheless, this way of thinking can tear away the concepts and preconceived notions that come from day-to-day contact with things as they are. Such speculation, moreover, is a good first step toward setting up some fertile demonstration models.

A recent large-scale study of the vast school health program of the New York City Health Department $(y)$ revealed some of the kinds of errors we can sometimes be lulled into tolerating. It showed, for example, that the very specially trained public health nurses were actually performing almost exactly the same functions as regular professional nurses. Professional nurses of all groups were spending almost half of their time on duties which nonprofessionals could, and should, perform. One can deduce from the study data that if the time the nurses spent on incidental activities could be devoted to nursing, the result would be the equivalent of increasing the number of nurses by 50 percent. This increase in manpower is far beyond anything the New York City Health Department has been able to match by any of the other means it has tried. As a result of this study, a new team approach is now being used to insure more efficient use of all school health personnel.

When we discuss shortages of personnel with particular titles, we tend to solidify the present. Implicit in much of our thinking is the idea that the same kinds of professionals will remain our basic human resources in the future.

The activities of our health personnel have actually been changing so radically, however, that one wonders that even their titles have remained the same. The rise in specialization has altered the sanctified relationship between physician and sick human being until it approaches more nearly a relationship between the physician and the patient's liver or other organ. While organs are recognized as being parts of human beings, the picture of the organ is sharp; the picture of the human qualities of the patient to whom it is attached, fleeting and fuzzy. To predict what the physician will be in a decade or two is not easy, but he will not be the same as he is today.

The nurse has undergone an even more spectacular metamorphosis. Once assigned only to the most menial tasks, she had to claw her way to a meaningful role in patient care. Now she suddenly hears the repeated suggestion that the professional nurse should not nurse the patient but make sure that somebody else does.

Not only will our nurse of the future be different, but changes in her duties will affect future recruiting. If patient care is no longer 
to be the core of what nurses do, nursing will attract different kinds of people than in the past. This change is not 100 percent bad. We need brilliant administrators who may not be directly in contact with patients. But there is danger that the most meaningful personal contact with the patient may be left to the cleaning woman.

When suggestions are made for changing the roles of various professionals, the voltage rises sharply, sparks fly, and great ohms of resistance develop in defense of positions gained through years of rolesmanship. Yet most changes come about not so much because of arbitrary decisions but under the pressure of changing needs. If a sufficient charge is realistically applied, it can cause an amazing degree of movement.

\section{Questions About Current Training Programs}

You will make up your own minds as to how well the various programs under consideration are working and what recommendations should be made. But perhaps I can ask a few questions about five Government training programs related to public health, knowing that you will provide final and correct answers to them, as well as to many additional questions.

1. Traineeships for physicians, engineers, nurses, and other professional health personnel for graduate or specialized training in public health. These traineeships are really scholarships-often used by young professional workers who cannot otherwise afford graduate education. Nurses planning to work for public health agencies have extensively used the program. Do enough key people know this program exists? Could communications about it be improved to attract more trainees? Is there too much recruitment of older candidates, conducted largely because of their experience, and too little recruitment of the young and eager who need experience? Are we imaginative enough in searching for new kinds of training and the broadly based curriculums required by our modern health programs? Should a plan be devised to adjust living expense stipends to the cost of living, which varies so greatly from one area to another and from one personal situation to another?

2. Traineeship grants to medical and dental students participating in preceptor-guided ap- prenticeships in public health and preventive medicine and dentistry. This is the only one of the five programs with emphasis on nongraduate students. Most medical students have to earn something during vacations; these traineeship grants make it possible for them to earn and learn within the health field. This program, under which some students have become the patient's advocate, may be exceedingly valuable in helping introduce students to what medicine is all about. Should it be expanded? Can we obtain more concrete evidence that it is meeting the needs for which it was designed? How can the program be improved? Are there other professional groups which should receive this type of training?

3. Preventive medicine and dentistry residency programs. Graduate residencies in preventive medicine and dentistry include 1 year of academic training plus 2 years of field experience, which may be in city or State health departments. They provide in-depth experience in public health practice for those entering the public health field as a career, and they are showing an encouraging increase. We should consider whether these residencies properly prepare the resident for the public health of the future. Are there better places and better circumstances to learn about community medicine than in city or State health departments? Do these residencies keep young physicians and dentists in close enough contact with the growing patient-care aspects of public health? Do we need to place more emphasis on intermittent, part-time, continuation education instead of concentrating solely on the intensive, full-time, academic program?

4. Project grants to schools of public health and to other public or nonprofit institutions providing graduate or specialized training in public health. Project grants to schools of public health and to other public or nonprofit institutions providing graduate or specialized public health training are frequently considered successful if significant numbers of students go on to public health careers. Is this our only goal? Are we primarily interested in motivating people to go into public health full time? Or are we more interested in creating an awareness of public health throughout the total gamut of health personnel? I sometimes think 
that a master of public health program might be an excellent background for the future medical school dean. Is this project support being given for a sufficient number of years to be a real factor in public health training? Can the various projects be molded into a unified training program? Are there undesirable emphases which distort the program's usefulness? How does support from this program relate to non-Federal sources of funds?

5. "Formula grants" to schools of public health to help meet the costs of training federally sponsored students. The money issued in formula grants to accredited schools of public health is intended to support the provision of public health training in schools of public health by offsetting a portion of the difference between the schools' income from tuition and the cost of instruction of federally supported trainees. This program is probably the most valuable source of money the school receives because of the great flexibility with which the funds may be used. Has the program been used wisely to support innovation in the preparation of our health manpower? Are some of the projects it has supported-such as continuation education-now ready to be taken over by a more permanent and regular financing scheme so that these flexible funds can continue to be used for innovation? Can the schools justify major increases in this source of funds?

While these five programs do not represent the total training effort of the Government relating to public health, a survey of them reveals an unevenness in support for health manpower. The medical student, for example, is all but left out. There is little Federal money to put him through school and very little to introduce him to health problems as they exist for the average citizen today. The medical student is, in general, isolated from the real needs, and much of what he is taught is irrelevant to them. Similarly, major support to create and improve the sadly deficient departments of community medicine in professional schools is greatly needed.

Nor are these by any means the only omissions. The overall program, although effective, must become far more need oriented. We are finally attaining enough intellectual and political maturity to become aware of our needs, to face up to them, and to realize that they, more than our pet theories, must guide future efforts in health manpower training. We must also insure that all of these programs promote, rather than interfere with, the integrity of our educational institutions.

\section{Attacking Health Problems on Broad Front}

The application of our medical resources is today to a large degree irrelevant to the problems and the opportunities of disease control. It is generally accepted that there are four stages of medicine. The first is the predisease stage, when factors are active which may lead to disease. The second stage is the beginning of disease. In this stage we can detect high blood-sugar levels in the man who does not yet have frank diabetes. Here, if we looked, we would find in the population the precursors of many diseases. In the third stage, that of frank disease, the patient has symptoms. He feels sick and is likely to demand help. The fourth stage is that of rehabilitation, in which the chronically ill person is helped to live with his handicap.

If we were to survey all the people serving in our patient care establishment today, we would find most of them engaged in the practice of third-stage medicine, for which the hospital bed and gleaming operating room are the symbols. It is true that we pay some attention to firststage medicine. We vaccinate children, although, as Yerby (8) notes, even here we are not uniformly successful. There is a tremendous gulf between the vaccination status of whites compared with Negroes. We tend to exercise preventive medicine when prevention is easy and can be administered in a dose or two. We also provide safe drinking water and uncontaminated food. These measures are comfortable traditional programs. Beyond this, we practice little first-stage medicine so far as the major problems of the day are concerned-especially such problems as heart disease and lung cancer.

If we could motivate youngsters to use good sense in their total food and fat intake, in their ratio of saturated to polyunsaturated fats, and in their habits of exercise, and could induce them not to smoke, prevention of this kind might help avoid hundreds of thousands of deaths annually from heart disease alone, as well as untold disability. We not only spend little effort on such 
motivation, we perpetuate the error by putting only an infinitesimal effort into learning more about how we might better achieve our ends or scientifically evaluate our successes.

Our interest should center on the solution of health problems. Community medicine is not the effort we expend; it is the actual provision for unmet health needs and the actual control of disease. We have not been able to demonstrate that we have made a dramatic impact upon the untold diseases in our population by use of third-stage medicine. Yet we concentrate the bulk of our brains and facilities on this stage.

Only a few medical conditions of public health importance were ever controlled thoroughly by third-stage medicine. Two of significance which occur offhand are lobar pneumonia in young people and appendicitis. Even in tuberculosis, the thrust is really in the first stage. It is in this stage that we protect the well person by isolating infectious persons and also by raising the general standard of living. We certainly have not controlled syphilis and gonorrhea by thirdstage medicine, even though we have highly effective drugs to cure them. It is only a small exaggeration to say that here is the classic combination of perfect treatment with an inadequate program of application.

American medicine today says to the patient, "Go away, don't bother us until you're sick." So the person waits for symptoms. And if that person is a woman with cancer of the cervix, which could have been successfully treated in its earliest stage, the disease often becomes incurable. If the person is a man with cancer of the lung, it is usually too late by the time symptoms drive him to the physician. When we are fortunate enough to save an occasional patient with such conditions by means of surgery, we tend to pat ourselves on the back and talk about medical miracles. We need more miracles, but we should have kept the person from getting lung cancer in the first place. A lot of what we do in medicine is mopping up, an operation in which we use medical miracles in an often forlorn attempt to repair medical mistakes, especially mistakes of omission. A high percentage of what we do in third-stage medicine would be unnecessary if adequate attention were given to first- and second-stage medicine. If sufficient research attention were paid to health problems in these first two stages, even more could eventually be done to solve them.

In short, medical care is far more than a political and economic service, important as these disciplines are to its success. It is much more also than meeting the demands for medical care of the individual patient efficiently, freely, and cheaply. In the current state of our indifferent success against the major killers and disablers, medical care is primarily a matter of the earliest and most complete application of effective biomedical and social science-that is, if our major goal is disease control rather than patient satisfaction.

There are, for example, at least nine ways by which cancer of the lung might, in theory, be controlled.

1. The person could stop smoking.

2. He could switch to cigars or a pipe.

3. Science might learn how to remove the tars from cigarettes.

4. Science might learn to remove the carcinogenic agent or agents in the tar.

5. We might discover an antidote to the carcinogenic agents of tar.

6. Since only about one or two of every 20 heavy smokers get lung cancer, we might learn to identify the persons who are particularly susceptible and concentrate on motivating them not to smoke.

7. We could develop better treatment, better surgery, and better radiation for the disease.

8. We might learn how to detect the lesion earlier in its course so that opportunities for cure would be improved.

9. We might some day develop a cancer preventive.

We do not know on which front results will come fastest. All reasonable avenues have to be considered. As far as the stopping of smoking is concerned, the biologic knowledge that to do so would help is there, but effective motivation is not. We do not have a preventive regimen that large numbers of people will accept and use. We do not know how to remove the carcinogenic agent from cigarettes as yet, but work is going on. Decades may be needed to establish the anti-cancer effectiveness of a filter, even if a good one is developed.

We have not yet developed an antidote to the carcinogenic agent of tar, but perhaps we have 
not worked on the problem enough. When it comes to identifying smokers who are probably especially susceptible, we are beginning to collect evidence. For example, asbestos workers are unusually susceptible to the hazards of cigarette smoking, possibly because the toxic agents collect in the asbestos particle within the lung. There may be other aspects of susceptibility, perhaps genetic.

What about better treatment? Some programs for detecting lung cancer have improved survivorship to a degree. What about a cancer preventive? We have not found one yet, but there is much research and a few straws of hope in the wind.

In dealing with lung cancer and most of our other major health problems, we have to continue a pluralistic approach, probing for possible breakthroughs, which may come anywhere along a broad front and may be made by any of a score of different disciplines. If the goal in community medicine is really to solve a problem, it is wrong to put all our chips on one number.

Often it is best to apply pressure on the system-have manufacturers list the tar contents of cigarettes or have hazards noted on labelsand to move gradually toward making lung cancer unacceptable.

Consider the high mortality rate among Negro infants. The reasons for it appear to be socioeconomic rather than genetic. There is a combination of factors, all of which add to the risk-for example, less prenatal care and the fact that the Negro mother coming home from the hospital often has to go to work right away. Since there may be no one to help her with other children, the new baby probably gets a smaller portion of her total time than in more affluent homes. The average Negro homes, too, are not as well heated, as well ventilated, or as air conditioned as average white homes. The Negro mother's sensitivity to the problems of the child may, for many reasons, be lower than that of the average white mother. In large families, the risk of infection is also greater. For a variety of reasons Negro parents are not as likely to follow through on the physician's recommendations. And it is usually particularly difficult for the Negro family to get medical care.

An attack on this real health problem has to include a great many activities, some beyond the traditional confines of medicine. The problem will not be solved simply by provision of more and earlier prenatal care, even though that is desirable. It will not be solved by vaccination, although appropriate immunizations in the first year of life are desirable. It will not be solved even by sudden lump sum payments to families, even though a rise in family income is desirable. It will not be cured simply by providing better buildings for the people to live in, although better homes are needed. The problem is complex, caused by many factors working together. It will give way eventually to a pluralistic approach, to many attacks mounted together, to many disciplines working together-disciplines which perhaps to an increasing degree will be trained together.

\section{Advances in Health Training to Date}

Much progress has been made since last we met. Evaluation of public health education programs reveals impressive data indicating a sharp rise in the number of people trained. Medical schools, schools of public health, and other professional schools have come into being dedicated to modern concepts of health teaching. Older traditional professional schools are rediscovering the community and adjusting their curriculums to include it. Universities are developing health careers programs in institutions from community colleges to full graduate schools.

The team concept of medicine in the service of the community has come of age in dozens of projects of the Office of Economic Opportunity and the Public Health Service around this land. An effective health services research center appears well on its way to reality. The Public Health Service has indicated the seriousness of its dedication to the improvement of health manpower by raising its component responsible for efforts in this field to full bureau status. One of the units, the Health Manpower Intelligence Branch, is scanning health manpower needs and studying the impact upon these needs of various types of health professional and subprofessional workers. Congressional action to improve State merit systems appears assured. The Professional Examination Service of the American Public Health Association has demonstrated its ability to raise the quality of health professionals through its interesting 
projects in the evaluation of health training and the creation of testing programs for new categories of personnel.

A large number of prestigious committees and commissions have recommended major innovations in health training programs. It is now up to us to translate some of these wise recommendations into programs of practical action.

\section{Conclusion}

We have a responsibility not to alienate ourselves from the reality of the problems we have to solve. How easy it is to stop thinking about the patient as a human being and to become preoccupied with the details of his lung or liver. How easy it is to stop thinking about the job to be done and to concentrate instead on the prerogatives of this or that group of professionals or on the prerogatives of a particular type of academic institution. How easy it is to be dazzled by a brilliant 6 -hour surgical operation that saved a life and to forget that in Mississippi every day Negro mothers having babies are six times as likely to die in the process as the average white woman in the United States.

How easy it is for us to become alienated from the future, which is misty and difficult to see, and to cling instead to the trappings of the present-trappings which though clear, familiar, and comfortable may become largely irrelevant during the next few years.

Nothing is set, nothing is definite, the experiment is perilous. But its very difficulty is what makes it exciting and worthy of our greatest efforts.

\section{REFERENCES}

(1) Vickers, G.: What sets the goals of public health. Lancet 599-602, Mar. 22, 1958.

(2) White-nonwhite differentials in health, education, and welfare. HEW Indicators (Department of Health, Education, and Welfare, Office of the Undersecretary), February-October, 1965.

(3) Burns, E. M. : Social policy and the health services : The choices ahead. Amer J Public Health 57 : 199-212, February 1967.

(4) Coggeshall, L. T. : Planning for medical progress through education. Association of American Medical Colleges, Evanston, Ill., April 1965.

(5) Darley, W., and Somers, A. R.: Medicine, money and manpower-The challenge to professional education. III. Increasing personnel. New Eng J Med 276: 1414-1423, June 22, 1967.

(6) Extra hands for the busy doctor. Med World News 8: 70, Feb. 24, 1967.

(7) School health personnel utilization project. Report on phase 1. A study of utilization patterns : methodology and findings. Medical and Health Research Association of New York City, Inc., in cooperation with the Department of Health of the City of New York, December 1966. (Summarized in Public Health Rep 82: 862-866, October 1967.)

(8) Yerby, A. : Paper presented at Conference on Barriers to Utilization of Health Services, Albany, N.Y., Mar. 14, 1967.

\section{Anesthesiology Research and Training Center}

A research and training center in anesthesiology, the first of its kind, will be established at the University of Pennsylvania with a $\$ 210,000$ Public Health Service grant. Teams of scientists from many disciplines and with a variety of special skills will study modern anesthesiology. The normal hazards of anesthesia are compounded today by the widespread use of medicines which have unpredictable chemical interaction with anesthetics.

Ranging from basic to clinical, the research will attempt to determine the effects of various anesthetics on cells, tissues, nerves, blood, respiration, and metabolism on humans and animals.

The program of the new center will extend and complement the present research and training program of Dr. Robert D. Dripps, chairman of the department of anesthesia and a pioneer in anesthesiological research in this country, and his associates. 